\title{
Revisa

\section{A ROSA É UMA ROSA É UMA ROSA? Um livro, um filme, uma série e a pluralidade de sentidos e possibilidades da arte narrativa a partir da obra de Umberto Eco ${ }^{1}$}

\author{
Eduardo Cesar Maia²
}

Considerada, a princípio, por alguns editores, uma obra extremamente difícil e que estava fadada ao fracasso mercadológico, O nome da Rosa, do semiólogo e historiador italiano Umberto Eco, surpreendeu a todos: milhões de exemplares foram vendidos em todo o mundo e a obra, hoje, encontra-se traduzida em cerca de 20 idiomas. Um êxito editorial avassalador e inesperado, se levarmos em conta justamente a complexidade de um texto permeado por discussões teológicas, filosóficas e por citações em latim sem tradução.

O romance é propositalmente aberto a vários níveis de leitura - uma máquina de gerar interpretações, disse Eco -, de acordo com o gosto e a formação de quem o lê. $\mathrm{Na}$ superfície, funciona perfeitamente como uma boa história de mistério e investigação completamente acessível a qualquer leitor. Nesse sentido, algumas referências literárias são evidentes, como no sobrenome Baskerville, dado por Eco ao seu protagonista, em alusão ao conto de Arthur Conan Doyle protagonizado pelo talvez mais famoso detetive da história da literatura; e, também, ao caso da proximidade sonora do nome do jovem pupilo e auxiliar Adso (elementar!), o personagem-narrador que rivaliza em importância com o protagonista. É justamente a relevância de Adso no enredo que sugere uma nova possibilidade de leitura, a que aproxima a obra da estrutura de um Bildungsroman, ou romance de formação, gênero literário de larga tradição e grande importância no ocidente, desde pelo menos Os anos de aprendizagem de Wilhelm Meister, de Goethe.

Em outra perspectiva, o livro pode ser visto ainda como um ambicioso romance histórico, permeado de detalhes sobre o mundo e a cosmovisão medieval, na qual Eco era, como se sabe, um grande especialista. Seguindo essa mesma linha, para um leitor um pouco mais preparado, O nome da Rosa pode ser analisado inclusive como uma obra

1 Ensaio publicado inicialmente na edição 235 da Revista Continente, em julho de 2020.

2 Crítico cultural, professor do Programa de Pós-Graduação em Letras e professor da graduação em Comunicação Social, ambos da UFPE. Contato: eduardo.ferreirafo@ufpe.br 


\section{Crises}

de reflexão filosófica bastante ambiciosa, que consegue trazer, a partir da reconstrução literária do contexto das disputas intelectuais, religiosas e políticas medievais, problematizações atualíssimas e urgentes para nosso próprio tempo.

A história das aventuras de Guilherme de Baskerville e de seu caro discípulo Adso de Melk, enfim, em uma ocorrência tão feliz quanto rara, conquistou público e crítica com uma fórmula arriscada para os padrões daquele momento, baseada na mistura criativa e consistente entre o universo popular das histórias de mistério, de crimes e detetives, e a chamada alta cultura. O escritor italiano pensou numa obra ao mesmo tempo divertida (mas nunca vazia ou superficial), e que ajudasse, desde que se tenha disposição de enfrentar suas dificuldades, a construir bons leitores durante sua leitura.

\section{"Grande livro, insignificante filme"?}

Em 1986, seis anos após o lançamento do livro, o diretor Jean Jacques Annaud apresentava uma adaptação cinematográfica homônima do best-seller. A recepção crítica ao filme, protagonizado por Sean Connery e com alguns coadjuvantes de peso, no entanto, não foi das melhores: os resenhistas não perdoaram a "simplificação" e a superficialidade do roteiro, que teria focado exclusivamente nos aspectos detetivesco e romântico, em detrimento da densidade histórico-filosófica do romance e de suas diversas camadas de leitura. Uma verdadeira "traição", disseram. Jornais importantes da Itália chegaram a publicar resenhas com títulos como "Grande livro, insignificante filme" e "Um delito essa Rosa!". O próprio Umberto Eco, que não quis se pronunciar sobre o valor artístico da adaptação, tampouco foi à estreia da obra numa famosa sala de cinema em Florença, apesar do convite e das expectativas. $\mathrm{O}$ autor, no entanto, comentou que havia dado ao diretor toda a liberdade para abordar a narrativa como bem entendesse, pois o que estava sendo feito era uma outra obra, uma "obra paralela" à sua.

Em defesa do diretor, poderíamos questionar o seguinte: como, em uma dramatização audiovisual de cerca de 120 minutos de duração, alguém poderia condensar toda a pesquisa histórica, toda a discussão filosófica e todas as camadas interpretativas de um livro de mais de 500 páginas, fruto da inteligência e erudição de um dos maiores pensadores europeus do século passado? Talvez, no fim das contas, a 
escolha por enfatizar a trama detetivesca tenha sido, em outro sentido, um acerto que acabou dando uma cara própria, uma unidade e uma amarração narrativa que de outra maneira seria difícil de lograr cinematograficamente. Mas, claro: é incontestável que a maior parte da riqueza literária e, principalmente, intelectual do romance simplesmente foi ignorada por Annaud.

Trago toda essa contextualização do passado relacionada à recepção crítica do filme, e aos limites e problemáticas artísticas da adaptação, justamente porque agora nos encontramos diante de uma outra versão, desta vez no formato de minissérie televisiva, de O nome da Rosa - e as mesmas questões se nos impõem outra vez. Em entrevista recente, o ator John Turturro, protagonista e produtor da série, explicou que se decidiu por empreender uma adaptação em formato seriado justamente por achar que o filme apesar de bom em muitos sentidos - era muito limitado ao lidar com a riqueza intelectual do material que está nas páginas do livro de Umberto Eco. Muito mais tempo seria necessário, portanto, para tal empreitada, ou seja, para dar conta minimante do contexto historiográfico e da base filosófica que conformam a verdadeira estatura do romance. Nesse sentido, a parceria com Giacomo Battiato, um importante medievalista e romancista, foi parte fundamental do projeto idealizado por Turturro. Battiato participou da criação do roteiro e foi encarregado da direção da série.

Evidentemente, a nova adaptação tampouco é capaz de abarcar integralmente as camadas do romance, mas consegue explorar muito mais elementos do que o filme, ainda que nem sempre com a profundidade insinuada pelas palavras de Turturro.

\section{A nova série: perdas e ganhos}

A minissérie, exibida pelo serviço de streaming da Starz, é uma coprodução ítalogermânica e está dividida em oito capítulos, cada um deles com aproximadamente 50 minutos. O enredo básico acompanha, em linhas gerais, a estrutura do livro, a não ser pela ampliação do papel das mulheres na trama, coisa que não se dá nem no livro nem no filme. Os eventos são narrados pelo personagem Adso de Melk, que relembra, já na velhice, seu tempo de noviço, como dileto aprendiz do pensador (e detetive avant la lettre) Guilherme de Baskerville, verdadeiro protagonista da história. O velho Adso, que 


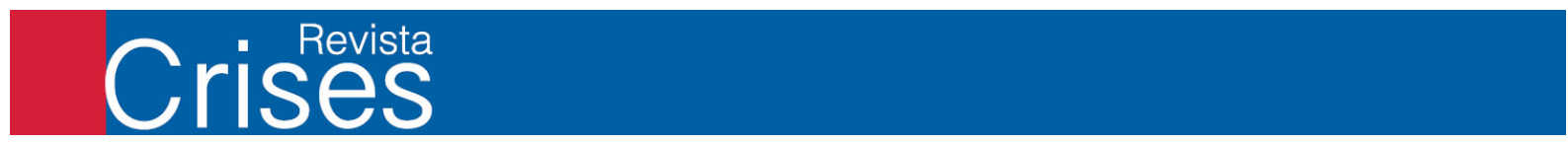

permaneceu na vocação religiosa, nos deixa seu testemunho sobre um período de sete dias durante o ano de 1327, quando tinha apenas 17 anos de idade, em que participou de eventos surpreendentes enquanto esteve como assistente de seu professor e amigo na resolução de uma série de crimes cometidos dentro de um convento beneditino. $O$ pano de fundo são as disputas religiosas que se desdobram, posteriormente, em confrontos bélicos entre Ludovico da Baviera, futuro imperador do Sacro Império Romano, que defendia a separação entre poder político e poder religioso, e o Papa João XXII, de origem francesa, que excomunga o adversário e reforça a concepção de que fora escolhido por Deus para manejar um poder absoluto, mesmo sobre os reis e, claro, sobre seus povos.

Os misteriosos assassinatos ocorrem nos dias que antecedem uma importante reunião entre diferentes ordens religiosas católicas, que precisam tratar de questões políticas da instituição e decidir como os franciscanos serão tratados dali em diante, já que começam a ser vistos como dissidentes pelo papado - desconfiança despertada pela defesa que a ordem fazia da virtude ligada à abnegação material para os religiosos e para a própria Igreja. Guilherme de Baskerville, que está entre os franciscanos, envolve-se nas duas frentes: enquanto investiga os crimes, ainda se revela um agudo crítico da estrutura eclesiástica, dos seus métodos e, até mesmo, de alguns de seus dogmas. Todo o charme do personagem está nessa espécie de estranhamento criado pela figura de um ironista cético em meio a um ambiente de fé opressiva. A personalidade tão deslocada em relação ao contexto de época por vezes nos deixa próximos à sensação de inverossimilhança, daí a importância de atores do calibre de Sean Connery, espetacular na versão cinematográfica; e John Turturro, não menos competente, e um pouco mais contido que seu predecessor, nesta nova entrega.

No papel de Adso de Melk está o jovem ator alemão Damian Hardung, que me parece realizar um trabalho mais consistente do que o desempenhado por Christian Slater no filme de 1986. A combinação sutil entre ingenuidade e uma espécie de fortaleza de espírito, aliada a uma bravura física em momentos de necessidade, ficaram melhor caracterizadas, a meu ver, no Adso de Hardung.

Merecem destaque, ainda, a interpretação sombria e convincente de Rupert Everett, que encarna o inquisidor Bernardo Gui, adversário intelectual e moral do 
protagonista. O personagem ganha mais peso na série - em relação, claro, ao filme justamente porque há mais tempo para a dramatização dos debates eclesiásticos e dos desdobramentos da investigação inquisitorial presidida por ele. Os melhores diálogos e situações dessa nova adaptação surgem precisamente dessa possibilidade de explorar um pouco mais o substrato filosófico do livro de Eco. Merecem destaque ainda as interpretações do herético Remigio de Voragine, por Fabrizio Bentivoglio, e do incômodo Salvatore, personagem que ficou marcado no cinema pela inesquecível atuação de Ron Perlman e que, agora, recebe uma nova caracterização na atuação competente de Stefano Fresi.

Como disse anteriormente, o maior tempo narrativo permite um ganho substancial da série em relação ao filme no que diz respeito à exploração do conteúdo intelectual da obra original. No entanto, em outro sentido, essa dilatação temporal gera também alguns problemas. O que poderia ser completamente investido nisso que apontei como ponto forte, foi também desperdiçado em tramas paralelas que pouco ou nada acrescentam à estrutura narrativa central, como no caso do alargamento excessivo da participação da jovem camponesa occitana, interpretada por Nina Fotaras, que recebe a proteção e o afeto de Adso. O mesmo ocorre com a personagem Ana (Greta Scarano), filha do Frei Dolcino, líder da seita herética que foi duramente reprimida por ordens do inquisidor Bernardo Gui. Ana, que sobreviveu ao massacre de toda sua família, aparece como uma espécie de Robin Hood solitário, que aparentemente está ali para reforçar a força e o papel feminino na narrativa, mas que não consegue se integrar à trama principal, o que explicita o artificialismo não do propósito - muito positivo - mas da execução artística.

No que diz respeito à fotografia, cenografia e ambientação, a minissérie vem recebendo muitos elogios. Na contramão deles, considero que as imagens são, em geral, claras demais, "limpas" demais. O clima opressivo sugerido pelo livro, e perfeitamente plasmada no filme de Annaud, não é alcançado na versão televisiva. Não se trata, evidentemente, de incompetência técnica, mas de uma escolha estética que me pareceu equivocada.

\section{A estranha atualidade do mundo medieval de Eco: um tratado sobre a intolerância}




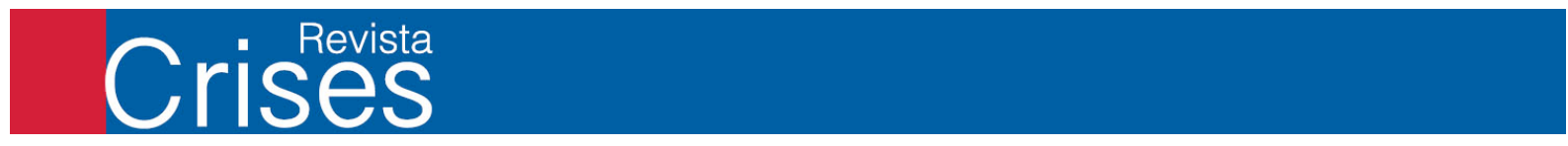

Não faz tanto sentido desmerecer filme ou série somente pela comparação com o livro. São projetos artísticos distintos, com propostas diferentes, e que têm seus próprios méritos e limitações. Podem ser comparados, claro, mas creio que cada um deve ser tomado em si mesmo, dentro de sua proposta particular, com suas virtudes e defeitos examinados a partir dessa singularidade. O mais importante, parece-me, é o que a leitura ou a experiência de assistir filme ou série pode nos proporcionar neste momento em que vivemos, em nossa própria medievalidade pós-moderna - expressão que me ocorreu ao retomar o contato com o universo de O nome da Rosa.

Destacarei um elemento em especial que está presente, em maior ou menor grau, no livro e em ambas as adaptações audiovisuais, e que contribui de maneira determinante para o nosso interesse contemporâneo. Trata-se da atitude intelectual de Guilherme de Baskerville - alter ego indisfarçável do escritor: um cético neonominalista que não aceita verdades não examinadas -, que é a de nunca se render a explicações totalizadoras e abstratas, e a de defesa do princípio de tolerância como virtude pessoal e social, em oposição às diversas formas de dogmatismo, seja religioso, ideológico ou mesmo àquelas manifestações de fanatismo intolerante que surgem a partir da corrupção do princípio crítico da filosofia ou da ciência. Afinal, os devaneios da razão também podem produzir seus monstros.

Os problemas filosóficos plasmados na ficção através dos debates entre os intelectuais da igreja continuam espantosamente atuais e nos alertam para a crise da linguagem e de valores que vivemos. O monge-detetive, assim como o autor, era um semiólogo: "Nunca duvidei da verdade dos signos"; e nunca procurava o conforto de uma verdade fixa e inabalável, o que deixava o seu pupilo Adso, educado dentro da visão universalista do tomismo, desconcertado: "Guilherme imaginava uma multiplicidade de respostas possíveis, muito distintas umas das outras; fiquei perplexo!". O seu professor insistia: "A beleza do cosmos não é dada somente pela unidade na variedade, mas também pela variedade na unidade". A pluralidade do mundo exige, como percebeu o noviço na convivência com seu tutor, uma disposição tolerante diante da variedade das perspectivas e valores humanos.

Guilherme de Baskerville acreditava que "O dever de quem ama os nomes é fazer rir da Verdade, porque a única verdade é aprender a nos liberar da paixão insana pela 


\section{Crises}

Verdade, (...), portanto, as únicas verdades que nos servem são instrumentos descartáveis". Essa liberação de "uma paixão insana" pode ser ilustrada pelo percurso intelectual do pensador italiano, que começou como católico progressista na juventude, aderiu à ortodoxia marxista aos $30 \mathrm{e}$, posteriormente, resolveu abandonar as grandes narrativas e as grandes verdades, como bom pós-moderno.

E m Migração e intolerância (2020), conjunto de ensaios de Umberto Eco recentemente publicado no Brasil pela Editora Record, encontramos a seguinte passagem: "Os intelectuais não podem lutar contra a intolerância selvagem, porque diante da animalidade pura, sem pensamento, o pensamento fica desarmado. E é sempre tarde demais quando resolvem lutar contra a intolerância doutrinária, pois quando a intolerância se faz doutrina é muito tarde para vencê-la, e aqueles que deveriam fazê-lo tornam-se suas primeiras vítimas". Curiosamente, esse trecho me remeteu não primeiramente a outros ensaios políticos ou filosóficos do autor, mas diretamente a O nome da Rosa. É que a ficção ambientada no mundo medieval, se bem lida, fala na verdade sobre os fundamentalismos e fanatismos presentes em todos os tempos, e muito marcadamente no nosso.

A linha de raciocínio de Eco sobre o tema se revela em muitas de suas obras, sejam literárias ou filosóficas: trata-se de defender o princípio da tolerância com base numa espécie de ceticismo gnoseológico baseado na aceitação de que só podemos conhecer a realidade de forma muito limitada, portanto não devemos permitir que um discurso único (seja político, religioso, científico etc.) nos diga o que somos, o que podemos e o que desejamos ser de maneira absoluta e definitiva.

Acompanhar essa nova minissérie baseada no grande romance de Eco pode ser uma oportunidade e porta de entrada para quem não conhece a riqueza do universo ficcional e intelectual de Umberto Eco, em um período histórico que desperta a advertência filosófica deixada pelo pensador: é preciso enfrentar a tendência demasiadamente humana de querer impor violentamente "verdades" políticas, ideológicas, religiosas e morais a outras pessoas e a outras culturas. 